\title{
Sodium tanshinone IIA sulfonate prevents lipopolysaccharide-induced inflammation via suppressing nuclear factor-KB signaling pathway in human umbilical vein endothelial cells
}

\begin{tabular}{|c|c|}
\hline Journal: & Canadian Journal of Physiology and Pharmacology \\
\hline Manuscript ID & cjpp-2017-0023.R1 \\
\hline Manuscript Type: & Article \\
\hline Date Submitted by the Author: & 23-Mar-2017 \\
\hline Complete List of Authors: & $\begin{array}{l}\text { Cheng, Jun; Southwest Medical University, Key Laboratory of Medical } \\
\text { Electrophysiology of Ministry of Education, Collaborative Innovation Center } \\
\text { for Prevention and Treatment of Cardiovascular Disease, Institute of } \\
\text { Cardiovascular Research } \\
\text { Chen, Tangting; Southwest Medical University, Key Laboratory of Medical } \\
\text { Electrophysiology of Ministry of Education, Collaborative Innovation Center } \\
\text { for Prevention and Treatment of Cardiovascular Disease, Institute of } \\
\text { Cardiovascular Research } \\
\text { Li, Pengyun; Southwest Medical University, Key Laboratory of Medical } \\
\text { Electrophysiology of Ministry of Education, Collaborative Innovation Center } \\
\text { for Prevention and Treatment of Cardiovascular Disease, Institute of } \\
\text { Cardiovascular Research } \\
\text { Wen, Jing; Southwest Medical University, Key Laboratory of Medical } \\
\text { Electrophysiology of Ministry of Education, Collaborative Innovation Center } \\
\text { for Prevention and Treatment of Cardiovascular Disease, Institute of } \\
\text { Cardiovascular Research } \\
\text { Pang, Ningbo; Southwest Medical University, Drug Discovery Research } \\
\text { Center; Southwest Medical University, Laboratory for Cardiovascular } \\
\text { Pharmacology of Department of Pharmacology, The School of Pharmacy } \\
\text { Zhang, Liping; Southwest Medical University, Drug Discovery Research } \\
\text { Center; Southwest Medical University , Laboratory for Cardiovascular } \\
\text { Pharmacology of Department of Pharmacology, The School of Pharmacy } \\
\text { Wang, Liqun; Southwest Medical University, Drug Discovery Research } \\
\text { Center; Southwest Medical University, Laboratory for Cardiovascular } \\
\text { Pharmacology of Department of Pharmacology, The School of Pharmacy }\end{array}$ \\
\hline \multicolumn{2}{|l|}{$\begin{array}{l}\text { Is the invited manuscript for } \\
\text { consideration in a Special } \\
\text { Issue?: }\end{array}$} \\
\hline Keyword: & tanshinone, lipopolysaccharide, inflammation, nuclear factor- $\mathrm{KB}$ \\
\hline
\end{tabular}


SCHOLARONE ${ }^{\text {'m }}$

Manuscripts

https://mc06.manuscriptcentral.com/cjpp-pubs 


\section{Sodium tanshinone IIA sulfonate prevents lipopolysaccharide-induced} inflammation via suppressing nuclear factor-kB signaling pathway in human umbilical vein endothelial cells

Jun Cheng ${ }^{1, \#}$, Tangting Chen ${ }^{1, \#}$, Pengyun $\mathrm{Li}^{1}$, Jing Wen ${ }^{1}$, Ningbo Pang ${ }^{2,3}$, Liping Zhang ${ }^{2,3}$ and Liqun Wang ${ }^{2,3, *}$

${ }^{1}$ Key Laboratory of Medical Electrophysiology of Ministry of Education, Collaborative Innovation Center for Prevention and Treatment of Cardiovascular Disease, Institute of Cardiovascular Research, Southwest Medical University, Luzhou 646000, Sichuan, China;

${ }^{2}$ Drug Discovery Research Center, Southwest Medical University, Luzhou 646000, Sichuan, China;

${ }^{3}$ Laboratory for Cardiovascular Pharmacology of Department of Pharmacology, The School of Pharmacy, Southwest Medical University, Luzhou 646000, Sichuan, China.

* Corresponding author:

Liqun Wang, PhD

Drug Discovery Research Center, Southwest Medical University, 319 Zhongshan Road, Luzhou 646000, Sichuan, China;

Email: yy000213@163.com,

Phone: +86-0830-3161673, Fax: +86-0830-3161702

\# Jun Cheng and Tangting Chen contributed equally to this work. 
Abstract: Sodium tanshinone IIA sulfonate (STS), a water-soluble derivative of tanshinone IIA, has been demonstrated to have potent anti-inflammatory properties. However, the protective effects of STS on lipopolysaccharide (LPS)-induced inflammation in endothelial cells remain to be elucidated. In the present study, human umbilical vein endothelial cells (HUVECs) were used to explore the effects of STS on LPS-induced inflammation and the molecular mechanism involved. HUVECs were pretreated with STS for $2 \mathrm{~h}$, followed by stimulation with LPS. Then expression and secretion of tumor necrosis factor (TNF)- $\alpha$ and interleukin (IL)-1 $\beta$, and the activation of nuclear factor-kB (NF-kB) were assessed. The results demonstrated that STS significantly decreased LPS-induced TNF- $\alpha$ and IL-1 $\beta$ protein expression in HUVECs. Similarly, the increased levels of TNF- $\alpha$ and IL-1 $\beta$ in cell supernatants stimulated by LPS were also significantly inhibited by STS. Furthermore, STS inhibited LPS-induced NF-kB p65 phosphorylation and nuclear translocation. All the results suggest that STS prevent LPS-induced inflammation through suppressing NF-KB signaling pathway in endothelial cells, indicating the potential utility of STS for the treatment of inflammatory diseases.

Key words: tanshinone, lipopolysaccharide, inflammation, nuclear factor-kB 


\section{Introduction}

The inflammation response of endothelial cells plays a critical role in the pathogenesis of various diseases, such as endotoxic shock, atherosclerosis and diabetes mellitus (Medzhitov 2008; Meigs et al. 2004). Inflamed endothelial cells express and release a range of proinflammatory cytokines, chemokines, and adhesion molecules, which are vital to evoke innate immune response and endothelial dysfunction (Meng et al. 2010; Zeng et al. 2005). Lipopolysaccharide (LPS), one of the main inflammatory pathogen in sepsis shock and atherogenesis (Alexander and Rietschel 2001; Cohen 2002; Hack and Zeerleder 2001), can directly activate endothelial cells and induce the expression and secretion of cytokines such as tumor necrosis factor (TNF)- $\alpha$ and interleukin (IL)-1 $\beta$ (Hu et al. 2009; Liu et al 2015; Pontillo et al. 2013). And the transcription factor nuclear factor-kB (NF-kB) signaling pathway has been demonstrated to play an important role in LPS-induced inflammation response (Baker et al. 2011; Dauphinee and Karsan 2006; Khakpour et al. 2015; Zhang and Ghosh 2000).

Danshen, also known as Salvia miltiorrhiza, is a promising and increasingly researched traditional Chinese herbal medicine that has been widely used for many years to treat various diseases including coronary artery disease, myocardial infarction, stroke, atherosclerosis and cerebrovascular disorders (Han et al. 2008; Zhou et al. 2005). Sodium tanshinone IIA sulfonate (STS, molecular structure shown in Fig. 1.) has been developed as a water-soluble derivative of tanshinone IIA which is one of the most pharmacologically active monomers extracted from Danshen. STS or tanshinone IIA has been demonstrated to induce vasodilation (Fan et al. 2011; 
Morton et al. 2015; Wu et al. 2009), inhibit inflammatory response (Li et al. 2015; Lu et al. 2016; Yang et al. 2016) and prevent atherosclerosis (Chang et al. 2014; Chen et al. 2012; Chen and Xu 2014; Fang et al. 2008) as well as cardiac injury (Gao et al. 2012; Jiang et al. 2009) and hypertrophy (Feng and Zheng 2008; Weng et al. 2015; Yang et al. 2007). Tanshinone IIA has also been reported to prevent LPS-induced inflammation response in acute lung injury (Xu et al. 2015) and in RAW264.7 macrophages (Fan et al. 2016; Jang et al. 2006) via inhibition of the NF-kB pathway. Human umbilical vein endothelial cells (HUVECs), an endothelial cell line derived from human umbilical veins, are commonly used for in vitro experimental models of vascular endothelial cells (Liang et al. 2013). Besides, there are no studies that have examined the effects of STS on LPS-induced inflammation in HUVECs.

In this study, we hypothesized that STS would prevent LPS-induced proinflammatory cytokine expression and secretion via suppressing NF-kB signaling pathway in HUVECs.

\section{Materials and methods}

\section{Reagents}

Primary human umbilical vein endothelial cells (HUVECs) and Medium 200 were purchased from Cascade Biologics (Portland, OR, USA). STS (purity $\geq 98 \%$ ) was from National Institutes for Food and Drug Control (Beijing, China). LPS was purchased from Sigma (St Louis, MO, USA). Antibodies to TNF-a, IL-1 $\beta$, phosphorylated NF-kB p65, total NF-kB p65, phosphorylated IkBa, total IKBa and GAPDH were form Cell Signaling Technology (Beverly, MA, USA). Fluorescein isothiocyanate (FITC)-conjugated anti-rabbit IgG was obtained from Molecular Probes (Eugene, OR, USA). Human IL-1 $\beta$ and TNF- $\alpha$ 
enzyme-linked immunosorbent assay (ELISA) kits were from R\&D Systems (Minneapolis, MN, USA). Cell Counting Kit 8 (CCK8) solution and NF-KB inhibitor, BAY11-7082 were from Beyotime (Shanghai, China). STS was dissolved in phosphate buffer saline (PBS) to obtain a $1 \mathrm{mg} / \mathrm{mL}$ stock solution.

\section{Cell culture}

HUVECs were grown in Medium 200 with a low-serum growth supplement. Cells passed 3-7 times were used.

\section{Cell viability assays}

HUVECs $\left(1 \times 10^{4} /\right.$ well $)$ were added to 96 -well plates and grown to confluence. Then cells were exposed to serum-free medium for $12 \mathrm{~h}$, followed by treatment with STS $(0,10,20,40$ and $80 \mathrm{mg} / \mathrm{mL})$ for $24 \mathrm{~h}$. To investigate the effects of STS on LPS-mediated cell viability, HUVECs were pretreated with STS $(0,10,20$ and $40 \mathrm{mg} / \mathrm{mL})$ for $2 \mathrm{~h}$, followed by stimulation with LPS (1 $\mu \mathrm{g} / \mathrm{mL}$ ) for $24 \mathrm{~h}$. Cell viability was measured with CCK8 solution at $450 \mathrm{~nm}$ using a Spectra Max M5 microplate reader (Molecular devices, Sunnyvale, CA, USA).

\section{Immunoblotting}

HUVECs $\left(3 \times 10^{5} /\right.$ well $)$ were plated on 6 -well plates and grown to confluence. Then cells were exposed to serum-free medium for $12 \mathrm{~h}$. To investigate the effects of STS on LPS-induced cytokine expression, cells were pretreated with STS $(0,10,20$ and $40 \mathrm{mg} / \mathrm{mL})$ for $2 \mathrm{~h}$, followed by stimulation with LPS $(1 \mu \mathrm{g} / \mathrm{mL})$ for $24 \mathrm{~h}$. To determine the effects of STS on LPS-induced NF-kB activation, cells were stimulated with LPS $(1 \mu \mathrm{g} / \mathrm{mL})$ for $4 \mathrm{~h}$ after pretreatment with STS $(0,10,20$ and $40 \mathrm{mg} / \mathrm{mL})$. Then cells were lysed and protein concentration was determined by BCA protein assay kit (Beyotime). In 
some experiments, nuclear and cytoplasmic proteins were prepared using nuclear extraction reagents (Pierce, Rockford, USA) according to the manufacturers' protocol. Protein samples were separated by sodium dodecyl sulphate-polyacrylamide gel electrophoresis and transferred onto polyvinylidene fluoride membranes (Bio-Rad Laboratories, Hercules, CA, USA). The membranes were blocked with $5 \%$ nonfat dry milk solution for 1 hour at room temperature. The blocked membranes were probed with antibodies against TNF- $\alpha$ (1:1000), IL-1 $\beta$ (1:1000), phosphorylated NF-KB p65 (1:1000), total NF-KB p65 (1:1000), phosphorylated IKBa (1:1000), total IKBa $(1: 1000)$ and GAPDH $(1: 1000)$ overnight at $4{ }^{\circ} \mathrm{C}$, followed by incubation with a horseradish peroxidase-conjugated secondary antibody (Santa Cruz Biotechnology) specific to the primary antibody for $1 \mathrm{~h}$. Then membranes were treated with enhanced chemiluminescence reagents (Merck Millipore, Watford, UK) and protein signal was imaged using a ChemiDoc XRS instrument (Bio-Rad Laboratories). Image $\mathrm{J}$ was used to measure the density of bands.

\section{ELISA}

Cell culture supernatants were collected and levels of TNF- $\alpha$ and IL-1 $\beta$ were determined with ELISA kits according to the manufacturers' instructions.

\section{Immunofluorescent staining}

Immunofluorescent staining was applied to localize NF-KB p65. HUVECs grown on glass coverslips were pretreated with STS $(40 \mathrm{mg} / \mathrm{mL})$ for $2 \mathrm{~h}$, followed by stimulation with LPS $(1 \mu \mathrm{g} / \mathrm{mL})$ for $4 \mathrm{~h}$. Then cells were fixed with $4 \%$ paraformaldehyde and permeabilized in $0.5 \%(\mathrm{v} / \mathrm{v})$ Triton $\mathrm{X}-100$. Cells were incubated with the primary antibody (rabbit monoclonal antibody against human NF-kB p65, 1:100) overnight at $4{ }^{\circ} \mathrm{C}$. After washing with PBS, cells 
were incubated with FITC-conjugated secondary antibody (1:100) against the primary antibody applied and nuclei were stained with 4', 6-diamidino-2-phenylindole (DAPI). Cells were imaged with an EVOS digital microscope (Electron Microscopy Sciences, Hatfield, PA, USA).

\section{Statistical analysis}

All of the data were expressed as the mean \pm standard deviation (SD) of the mean. One-way analysis of variance was used to determine significant differences. $p<0.05$ was considered statistically significant.

\section{Results}

\section{Effects of STS on cell viability}

To identify whether STS treatment induced cell death, the effects of STS on cell viability were determined. The results showed no significant differences among the groups (Fig. 2A), indicating that at the maximum concentration of $80 \mathrm{mg} / \mathrm{mL}$, STS didn't affect HUVEC viability. Therefore, in the follow-up experiments, the highest concentration of STS we used was $40 \mathrm{mg} / \mathrm{mL}$. Then the effects of STS on viability of HUVECs stimulated with LPS were investigated. The results showed that LPS significantly decreased cell viability compared to that in vehicle control. However, STS remarkably prevented LPS-induced cell viability decrease (Fig. 2B).

\section{STS prevents LPS-induced TNF- $\alpha$ and IL-1 $\beta$ expression and secretion.}

To explore the effects of STS on LPS-induced inflammation response in HUVECs, the expression of proinflammatory cytokines, including TNF- $\alpha$ and IL-1 $\beta$, was determined using immunoblotting. The results showed that LPS significantly increased the expression of TNF- $\alpha$ (Fig. 3A) and IL-1 $\beta$ (Fig. 3B) compared to that in the vehicle control group, whereas, STS significantly 
inhibited LPS-induced TNF- $\alpha$ (Fig. 3A) and IL-1 $\beta$ (Fig. 3B) expression at the dose of 20 and $40 \mathrm{mg} / \mathrm{mL}$. Although $10 \mathrm{mg} / \mathrm{mL}$ STS also decreased TNF- $\alpha$ and IL-1 $\beta$ expression, there was no significant difference compared with that of LPS-stimulated cells. We also examined the effects of STS alone on TNF- $\alpha$ and IL-1 $\beta$ expression and the results showed no significant differences among the groups (Supplementary Figure S1).

To further identify the protective effects of STS on LPS-induced inflammation response in HUVECs, the levels of TNF- $\alpha$ and IL-1 $\beta$ in cell culture supernatants were measured by ELISA. Similarly, STS also decreased LPS-induced TNF- $\alpha$ and IL-1 $\beta$ secretion (Fig. 3C and 3D). As a whole, these results indicate that STS prevents LPS-induced inflammation response in HUVECs.

\section{STS prevents LPS-induced NF-KB activation in HUVECs}

NF-KB signaling plays a critical role in the regulation of LPS-induced inflammation response. To explore the molecular mechanism underlying the protective effects of STS against LPS-induced inflammation response, we examined the effects of STS on LPS-induced NF-KB activation. The phosphorylation of NF-kB p65 was assessed by immunoblotting. The results showed that treatment with LPS for $4 \mathrm{~h}$ significantly increased phosphorylation of NF-kB p65 in HUVECs (Fig. 4A). However, pretreatment with STS significantly inhibited LPS-induced increase in NF-kB p65 phosphorylation (Fig. 4A). To further clarify the effects of STS on LPS-induced activation of NF-kB pathway, some other mediators of NF-kB pathway, such as phosphorylated I $\mathrm{BB} \alpha$ and total IkBa were examined by immunoblotting. Consistent with the results involving phosphorylated NF-KB, we found that pretreatment with STS 
significantly inhibited LPS-induced phosphorylation and degradation of IKBa (Fig. 4B and 4C). We also examined the effects of STS alone on NF-KB activation and the results showed no significant differences among the groups (Supplementary Figure S2).

In addition, the effects of STS on LPS-induced NF-kB p65 nuclear translocation were evaluated. The results showed that STS significantly prevented LPS-induced increase of NF-KB p65 content in nuclear and decrease of that in the cytoplasm (Fig. 4D). Consistent with immunoblotting results, immunofluorescent staining also demonstrated that LPS-induced NF-kB p65 nuclear translocation was inhibited by STS pretreatment (Fig. 4E). As a whole, these results suggest that STS prevent LPS-induced NF-kB p65 activation and nuclear translocation.

\section{Blockade of NF-KB inhibits LPS-induced inflammation response}

Our results were not yet enough to declare that STS prevents LPS-induced inflammation response through inhibiting NF-KB signaling, although our data showed inhibitory effects of STS on LPS-induced NF-kB p65 activation. Therefore, the effects of blocking NF-KB signaling on LPS-induced inflammation response were examined. HUVECs were pretreated with BAY11-7082 $(10 \mu \mathrm{M})$, the specific inhibitor of NF-kB, for $1 \mathrm{~h}$, followed by stimulation with LPS $(1 \mu \mathrm{g} / \mathrm{mL})$ for $24 \mathrm{~h}$. The results showed that BAY11-7082 significantly inhibited LPS-induced TNF- $\alpha$ and IL-1 $\beta$ expression (Fig. 5A and $5 B$ ). And the levels of TNF- $\alpha$ and IL-1 $\beta$ in cell culture supernatants were also significantly decreased in BAY11-7082-treated cells (Fig. 5C and 5D). These results and previous experiments involving the inhibitory effects of STS on NF-KB activation at least, partially suggest that STS prevent LPS-induced 
inflammation response through suppressing NF-kB signaling pathway.

\section{Discussion}

In vivo and in vitro studies have shown that LPS exposure can trigger endothelial activation and endothelial inflammation response, resulting in the secretion of proinflammatory cytokines, which further contributes to pathogenesis of cardiovascular diseases (Dauphinee and Karsan 2006). Therefore, the identification of new therapeutic and preventive approaches targeting LPS-induced endothelial cell inflammation is crucial and has great clinical implications. In the present study, we investigated the effects of STS on LPS-induced inflammation in HUVECs. Our findings suggest that STS prevent LPS-induced TNF- $\alpha$ and IL-1 $\beta$ expression and secretion by inhibiting NF-kB activation.

It is well known LPS regulates cytokines, including TNF- $\alpha$ and IL-1 $\beta$, expression and secretion in endothelial cells (Hu et al. 2009; Liu et al 2015; Pontillo et al. 2013). Our data in this study also showed LPS significantly promoted TNF- $\alpha$ and IL-1 $\beta$ expression and secretion in HUVECs. We further found that pretreatment with STS inhibited the increase of cytokine expression and secretion stimulated by LPS. These results were consistent with previous studies which demonstrated that tanshinone IIA prevents LPS-induced inflammation in macrophages (Fan et al. 2016), endometritis (Lv et al. 2015), sepsis (Huang et al. 2015) and lung injury (Xu et al. 2015).

NF-kB, which consists of a heterodimer of p65 and p50 is preferentially localized in the cytoplasm with inhibitory IKB proteins under quiescent condition (Oeckinghaus A and Ghosh 2009). NF-KB signaling pathway plays an important role in LPS-regulated inflammation response. LPS induces IKBs 
phosphorylation and degradation, causing NF-KB to be phosphorylated, released and translocated into nucleus to activate target genes expression (Baker et al. 2011; Dauphinee and Karsan 2006; Khakpour et al. 2015; Zhang and Ghosh 2000). The results in this study also demonstrated that treatment with LPS for $4 \mathrm{~h}$ induced phosphorylation and degradation of $\mathrm{IKBa}$ and consequently increased NF-kB p65 phosphorylation and nuclear translocation. However, pretreatment with STS significantly inhibited LPS-induced IKB phosphorylation and NF-kB p65 activation. The experiments using BAY117082, the specific inhibitor of NF-kB, showed that blockade of NF-kB activation significantly inhibited LPS-induced inflammation response. Although these results do not directly prove the protective effects of STS were through inhibiting NF-KB pathway, combining the data of previous studies which investigated the roles of STS in LPS-induced macrophage inflammation (Fan et al. 2016) and mouse endometritis (Lv et al. 2015), our results at least, partially indicate that STS prevents LPS-induced inflammation via suppressing NF-kB signaling pathway.

Based on our data in the present study and those of published reports, it is conceivable that STS and Tanshinone IIA could be used to treat diseases associated with inflammation. However, the underlying mechanisms have not been fully elucidated. Especially, few experiments have attempted to uncover the direct target of STS in this study and previous reports. Therefore, further investigations are needed to better explore the therapeutic potential of STS or tanshinone IIA.

In summary, we have described a protective role of STS in inflammation in HUVECs and the molecular mechanism involved in the present study. Our 
results demonstrated that STS prevented LPS-induced inflammation through suppressing NF-KB signaling pathway. These novel findings indicate the potential application of STS for prevention and treatment of inflammation diseases in the clinical practice. 


\section{Conflict of Interests}

The authors declare that there is no conflict of interests regarding the publication of this paper.

\section{Authors' Contribution}

Jun Cheng and Tangting Chen carried out experiments. Pengyun Li and Jing Wen analyzed data. Ningbo Pang and Liping Zhang prepared samples. Liqun Wang designed the experiments and wrote the manuscript.

\section{Acknowledgments}

This work was supported by the Special Foundation of Luzhou City-Southwest Medical University (2013LZLY-J05), the Foundation of the Education Department of Sichuan Province (15ZA0162), the Foundation of the Health Department of Sichuan Province (120367) and the National Natural Science Foundation of China (81173661). 


\section{References}

Alexander, C., and Rietschel, E.T. 2001. Bacterial lipopolysaccharides and innate immunity. J. Endotoxin Res. 7: 167-202. PMID: 11581570.

Baker, R.G., Hayden, M.S., and Ghosh, S. 2011. NF-kB, inflammation, and metabolic disease. Cell Metab. 13: 11-22. doi: 10.1016/j.cmet.2010.12.008. PMID: 21195345.

Chang, C.C., Chu, C.F., Wang, C.N., Wu, H.T., Bi, K.W., Pang, J.H., et al. 2014. The anti-atherosclerotic effect of tanshinone IIA is associated with the inhibition of TNF-a-induced VCAM-1, ICAM-1 and CX3CL1 expression. Phytomedicine, 15: 207-216. doi: 10.1016/j.phymed.2013.09.012. PMID: 24157079.

Chen, W., Tang, F., Xie, B., Chen, S., Huang, H., and Liu, P. 2012. Amelioration of atherosclerosis by tanshinone IIA in hyperlipidemic rabbits through attenuation of oxidative stress. Eur. J. Pharmacol. 674: 359-364. Doi: 10.1016/j.ejphar.2011.10.040. PMID: 22088276.

Chen, Z., and Xu, H. 2014. Anti-inflammation and immunomodulatory mechanism of tanshinone IIA for atherosclerosis. Evid. Based Complement. Alernat. Med. 2014: 267976. doi: 10.1155/2014/267976. PMID: 25525444.

Cohen, J. 2002. The immunopathogenesis of sepsis. Nature, 420: 885-891. doi: 10.1038/nature01326. PMID: 12490963.

Dauphinee, S.M., and Karsan, A. 2006. Lipopolysaccharide signaling in endothelial cells. Lab. Invest. 86: 9-22. doi: 10.1038/labinvest.3700366. PMID: 16357866.

Fan, G., Jiang, X., Wu, X., Fordjour, P.A., Miao, L., and Zhang, H. 2016. 
Anti-inflammation activity of tanshinone IIA in LPS-stimulated RAW264.7 macrophages via miRNAa and TLR4-NF-kB pathway. Inflammation, 39: 375-84. Doi: 10.1007/s10753-015-0259-1. PMID: 26639663.

Fan, G., Zhu, Y., Guo, H., Wang, X., Wang, H., and Gao, X. 2011. Direct vasorelaxation by a novel phytoestrogen tanshinone IIA is mediated by nongenomic action of estrogen receptor through endothelial nitric oxide synthase activation and calcium mobilization. J. Cardiovasc. Pharmacol. 57: 340-347. doi: 10.1097/FJC.0b013e31820a0da1. PMID: 21383591.

Fang, Z.Y., Lin, R., Yuan, B.X., Yang, G.D., Liu, Y., and Zhang, H. 2008. Tanshinone IIA downregulates the CD40 expression and decreases MMP-2 activity on atherosclerosis induced by high fatty diet in rabbit. J. Ethnopharmacol. 115: 217-22. doi: 10.1016/j.jep.2007.09.025. PMID: 17997063.

Feng, J., and Zheng, Z. 2008. Effect of sodium tanshinone IIA sulfonate on cardiac myocyte hypertrophy and its underlying mechanism. Chin. J. Integr. Med. 14: 197-201. Doi: 10.1007/s11655-008-0197-y. PMID: 18853116.

Gao, S., Liu, Z., Li, H., Little, P.J., Liu, P., and Xu, S. 2012. Cardiovascular actions and therapeutic potential of tanshinone IIA. Atherosclerosis, 220: 3-10. doi: 10.1016/j.atherosclerosis.2011.06.041. PMID: 21774934.

Hack, C.E., and Zeerleder, S. 2001. The endothelium in sepsis: source of and a target for inflammation. Crit. Care Med. 29: S21-27. PMID: 11445730.

Han, J.Y., Fan, J.Y., Horie, Y., Mirua, S., Cui, D.H., and Ishii, H. Ameliorating effects of compounds derived from Salvia miltiorrhiza root extract on microcirculatory disturbance and target organ injury by ischemia and reperfusion. Pharmacol. Ther. 117: 280-295. doi: 
10.1016/j.pharmthera.2007.09.008. PMID: 18048101.

Hu, Y., Chen, X., Duan, H., Hu, Y., and Mu, X. 2009. Pulsatilla decoction and its active ingredients inhibits secretion of NO, ET-1, TNF-alpha, and IL-1 alpah in LPS-induced rat intestinal microvascular endothelial cells. Cell Biochem. Funct. 27: 284-288. doi: 10.1002/cbf.1570. PMID: 19472295.

Huang, L., Zheng, M., Zhou, Y., Zhu, J., Zhu, M., and Zhao, F. 2015. Tanshinone IIA attenuates cardiac dysfunction in endotoxin-induced septic mice via inhibition of NADPH oxidase 2-related signaling pathway. Int. Immunopharmacol. 28: 444-449. doi: 10.1016/j.intimp.2015.07.004. PMID: 26202805.

Jang, S.I., Kim, H.J., Jeonq, S.I., and You, Y.Q., 2006. Tanshinone IIA inhibits LPS-induced NF-kappaB activation in RAW 264.7 cells: possible involvement of the NIK-IKK, ERK1/2, p38 and JNK pathways. Eur. J. Pharmacol. 542: 1-7. doi: 10.1016/j.ejphar.2006.04.044. PMID: 16797002.

Jiang, B., Zhang, L., Wang, Y., Li, M., Wu, W., Guan, S., et al. 2009. Tanshinone IIA sodium sulfonate protects against cardiotoxicity induced by doxorubicin in vitro and in vivo. Food Chem. Toxicol. 47: 1538-1544. Doi: 10.1016/j.fct.2009.03.038. PMID: 19358873.

Khakpour, S., Wilhelmsen, K., and Hellman, J. 2015. Vascular endothelial cell Toll-like receptor pathways in sepsis. Innate Immun. 21: 827-846. doi: 10.1177/1753425915606525. PMID: 26403174.

Li, W., Zhang, Y., Xing, C., and Zhang, M. 2015. Tanshinone IIA represses inflammatory response and reduces radiculopathic pain by inhibiting IRAK-1 and NF-kB/p38/JNK signaling. Int. Immunopharmacol. 28: 382-389. doi: 10.1016/j.intimp.2015.06.032. PMID: 26163178. 
Liang, Q., Yu, F., Cui, X., Duan, J., Wu, Q., Naqarkatti, P., et al. 2013. Sparstoloinin B suppresses lipopolysaccharide-induced inflammation in human umbilical vein endothelial cells. Arch. Pharm. Res. 36: 890-896. doi: 10.1007/s12272-013-0120-8. PMID: 23604718.

Liu, Y., Bao, L., Xuan, L., Song, B., Lin, L., and Han, H. 2015. Chebulagic acid inhibits the LPS-induced expression of TNF- $\alpha$ and IL-1 $\beta$ in endothelial cells by suppressing MAPK activation. Exp. Ther. Med. 10: 263-268. doi: 10.3892/etm.2015.2447. PMID: 26170946.

Lu, B.L., Li, J., Zhou, J., Li, W.W., and Wu, H.F. 2016. Tanshinone IIA decreases the levels of inflammation induced by $A \beta 1-42$ in brain tissues of Alzheimer's disease model rats. Neuroreport, 27: 883-893. Doi: 10.1097/WNR.0000000000000618. PMID: 27348015.

Lv, X., Fu, K., Li, W., Wang, Y., Wang, J., and Li, H. 2015. TIIA attenuates LPS-induced mouse endometritis by suppressing the NF-kB signaling pathway. Can. J. Physiol. Pharmacol. 93: 967-971. doi: 10.1139/cjpp-2015-0003. PMID: 26426600.

Medzhitov, R. 2008. Origin and physiological roles of inflammation. Nature, 454: 428-435. doi: 10.1038/nature07201. PMID: 18650913.

Meigs, J.B., Hu, F.B., Rifai, N., and Manson, J.E. 2004. Biomarkers of endothelial dysfunction and risk of type 2 diabetes mellitus. JAMA. 291: 1978-1986. doi: 10.1001/jama.291.16.1978. PMID: 15113816.

Meng, G., Liu, Y., Lou, C., and Yang, H. 2010. Emodin suppresses lipopolysaccharide-induced proinflammatory response and NF-kB activation by disrupting lipid rafts in CD14-negative endothelial cells. Br. J. Pharmacol. 161: 1628-1644. doi: 10.1111/j.1476-5381.2010.00993.x. 
PMID: 20726986.

Morton, J.S., Andersson, I.J., Cheung, P.Y., Baker, P., and Davidge, S.T. 2015.

The vascular effects of sodium tanshinone IIA sulphonate in rodent and human pregnancy. PLos One, 26: e0121897. doi: 10.1371/journal.pone.0121897. PMID: 25811628.

Oeckinghaus, A., and Ghosh, S. 2009. The NF-kappaB family of transcription factors and its regulation. Cold Spring Harb. Perspect. Biol. 1: a000034. doi: 10.1101/cshperspect.a000034. PMID: 20066092.

Pontillo, A., Girardelli, M., Agostinis, C., Masat, E., Bulla, R., and Crovella, S. 2013. Bacterial LPS differently modulates inflammasome gene expression and IL-1 secretion in trophoblast cells, decidual stromal cells, and decidual endothelial cells. Reprod. Sci. 20: 563-566. doi: 10.1177/1933719112459240. PMID: 23184659.

Tian, X.H., and Wu, J.H. 2013. Tanshinone derivatives: a patent review (January 2006-September 2012). Exp. Opin. Ther. Pat. 23: 19-29. doi: 10.1517/13543776.2013.736494. PMID: 23094864 .

Weng, Y.S., Wang, H.F., Pai, P.Y., Jong, G.P., Lai, C.H., Chung, L.C., et al. 2015. Tanshinone IIA prevents Leu27IGF-II-induced cardiomyocyte hypertrophy mediated by estrogen receptor and subsequent Akt activation. 43: 1567-1591. Am. J. Chin. Med. Doi: 10.1142/S0192415X15500895. PMID: 26621443.

Wu, G.B., Zhou, E.X., and Qing, D.X. 2009. Tanshinone II(A) elicited vasodilation in rat coronary arteriole: roles of nitric oxide and potassium channels. Eur. J. Pharmacol. 617: 102-107. doi: 10.1016/j.ejphar.2009.06.046. PMID: 19576884. 
Xu, M., Cao, F.L., Zhang, Y.F., Shan, L., Jiang, X.L, and An, X.J. 2015. Tanshinone IIA therapeutically reduces LPS-induced acute lung injury by inhibiting inflammation and apoptosis in mice. Acta Pharmacol. Sin. 36: 179-187. doi: 10.1038/aps.2014.112. PMID: 25544360.

Yang, J.X., Pan, Y.Y., Ge, J.H., Chen, B., Mao, W., Qiu, Y.G., et al. 2016. Tanshinone IIA attenuates TNF- $\alpha$-induced expression of VCAM-1 and ICAM-1 in endothelial progenitor cells by blocking activation of NF-kB. Cell Physiol. Biochem. 40: 195-206. doi: 10.1159/000452537. PMID: 27855363.

Yang, L., Zou, X., Liang, Q., Chen, H., Feng, J., Yan, L., et al. 2007. Sodium tanshinone IIA sulfonate depresses angiotensin II-induced cardiomyocyte hypertrophy through MEK/ERK pathway. Exp. Mol. Med. 39: 65-73. Doi: 10.1038/emm.2007.8. PMID: 17334230.

Zeng, X.K., Guan, Y.F., Remick, D.G., and Wang, X. 2005. Signal pathways underlying homocysteine-induced production of MCP-1 and IL-8 in cultured human whole blood. Acta Pharmacol. Sin. 26: 85-91. doi: 10.1111/j.1745-7254.2005.00005.x. PMID: 15659119.

Zhang, G., and Ghosh, S. 2000. Molecular mechanism of NF-kappaB activation induced by bacterial lipopolysaccharide through Toll-like receptors. J. Endotoxin Res. 6: 453-457. PMID: 11521070.

Zhou, L., Zuo, Z., and Chow, M.S. 2005. Danshen: an overview of its chemistry, pharmacology, pharmacokinetics, and clinical use. J. Clin. Pharmacol. 45: 1345-1359. doi: 10.1177/0091270005282630. PMID: 16291709. 


\section{Figure legends:}

Fig. 1. The molecular structure of STS.

Fig. 2. Effects of STS on LPS-mediated cell viability. (A) HUVECs were exposed to STS $(0,10,20,40$ and $80 \mathrm{mg} / \mathrm{mL})$ for $24 \mathrm{~h}$. (B) HUVECs were pretreated with STS $(0,10,20$ and $40 \mathrm{mg} / \mathrm{mL})$ for $2 \mathrm{~h}$, followed by stimulation with LPS $(1 \mu \mathrm{g} / \mathrm{mL})$ for $24 \mathrm{~h}$. Cell viability was measured using the CCK8 assay. Data shown are mean \pm SD of 5 independent experiments, presented as a percent of the control value (first bar).

Fig. 3. STS prevents LPS-induced TNF- $\alpha$ and IL-1 $\beta$ expression and secretion in HUVECs. HUVECs were treated with STS $(0,10,20$ and $40 \mathrm{mg} / \mathrm{mL})$ for $2 \mathrm{~h}$, followed by stimulation with LPS $(1 \mu \mathrm{g} / \mathrm{mL})$ for $24 \mathrm{~h}$. (A and B) Expression of TNF- $\alpha$ and IL-1 $\beta$ was analyzed by western blotting. Representative images of 3 independent experiments and densitometric analysis of the levels of TNF- $\alpha$ and IL-1 $\beta$ normalized to that of GAPDH are shown. Data shown are mean \pm SD of 3 independent experiments, presented as fold changes. ${ }^{* *}, p<0.01$ compared with the control group (first bar); ${ }^{\#}, p<0.01$ compared with the LPS group. (C and D) The levels of TNF- $\alpha$ and IL-1 $\beta$ in cell culture supernatants were measured by ELSIA kits. Data shown are mean \pm SD of 3 independent experiments. ${ }^{* *}, p<0.01$ compared with the control group (first bar); ${ }^{\#}, p<$ 0.01 compared with the LPS group.

Fig. 4. STS prevents LPS-induced activation of NF-kB p65. HUVECs were incubated with STS $(0,10,20$ and $40 \mathrm{mg} / \mathrm{mL})$ for $2 \mathrm{~h}$, followed by stimulation with LPS (1 $\mu \mathrm{g} / \mathrm{mL})$ for $4 \mathrm{~h}$. (A, B and C) Cell lysates were prepared and subjected to western blotting to detect the phosphorylated (p) NF-kB p65, total NF-kB p65, phosphorylated (p) IкBa and total IкBa. Representative images of 
3 independent experiments and densitometric analysis of phosphorylated NF-kB p65 normalized to total NF-KB p65, phosphorylated IKBa normalized to GAPDH and total IkBa normalized to GAPDH are shown. Data are shown as mean \pm SD for 3 independent experiments and presented as fold changes. **, $p<0.01$ compared with the control group (first bar); ${ }^{\#}, p<0.01$ compared with the LPS group. (D) Nuclear and cytoplasmic NF-kB p65 were detected using western blotting. Representative images of 3 independent experiments and densitometric analysis of p65 normalized to GAPDH or nucleolin are shown. Data are shown as mean \pm SD for 3 independent experiments and presented as fold changes. ${ }^{* *}, p<0.01$ compared with the control group (first bar); ${ }^{\#}, p<$ 0.01 compared with the LPS group. (E) Cells grown on glass coverslips were pretreated with STS (40 mg/mL) for $2 \mathrm{~h}$, followed by stimulation with LPS (1 $\mu \mathrm{g} / \mathrm{mL}$ ) for $4 \mathrm{~h}$. Cells were fixed, permeabilized and stained with antibody directed against NF-kB p65 (Green). Distance bars, $50 \mu \mathrm{m}$. Representative images of 3 independent experiments are shown.

Fig. 5. BAY11-7082, the NF-KB inhibitor, inhibits LPS-induced TNF- $\alpha$ and IL-1 $\beta$ expression and secretion in HUVECs. HUVECs were treated with BAY11-7082 $(10 \mu \mathrm{M})$ for $1 \mathrm{~h}$, followed by stimulation with LPS $(1 \mu \mathrm{g} / \mathrm{mL})$ for $24 \mathrm{~h}$. (A and B) Expression of TNF- $\alpha$ and IL-1 $\beta$ was analyzed by western blotting. Representative images of 3 independent experiments and densitometric analysis of the levels of TNF- $\alpha$ and IL-1 $\beta$ normalized to that of GAPDH are shown. Data shown are mean $\pm S D$ of 3 independent experiments and presented as fold changes. ${ }^{* *}, p<0.01$ compared with the control group (first bar); ${ }^{\#}, p<0.01$ compared with the LPS group. (C and D) The levels of TNF- $\alpha$ and IL-1 $\beta$ in cell culture supernatants were measured by ELISA kits. Data 
shown are mean \pm SD of 3 independent experiments. ${ }^{* *}, p<0.01$ compared with the control group (first bar); ${ }^{\prime}, p<0.01$ compared with the LPS group. 


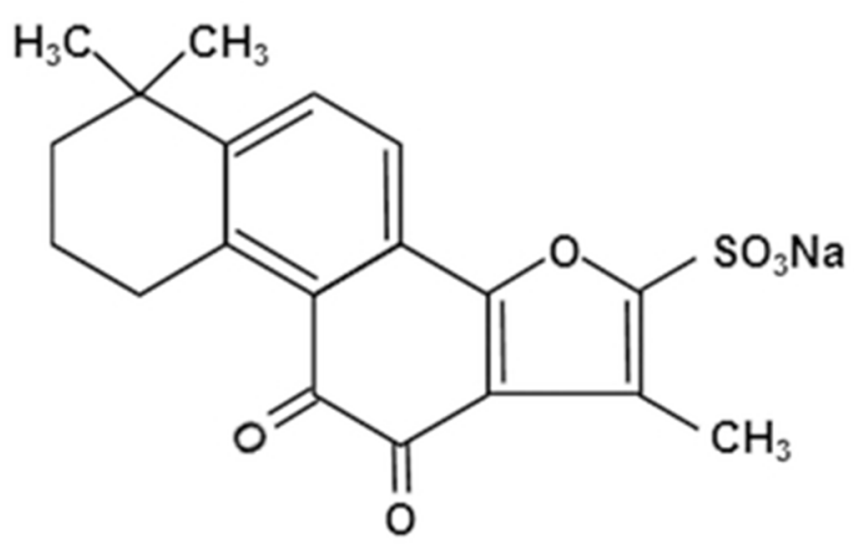

Fig. 1. The molecular structure of STS.

$29 \times 18 \mathrm{~mm}(300 \times 300 \mathrm{DPI})$ 
A

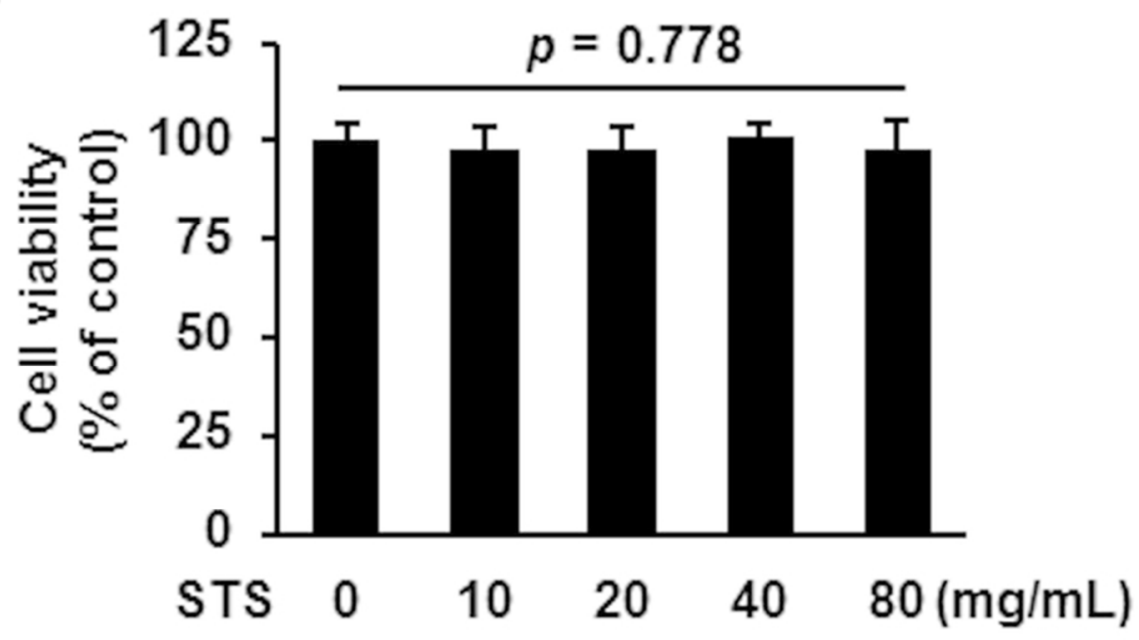

B

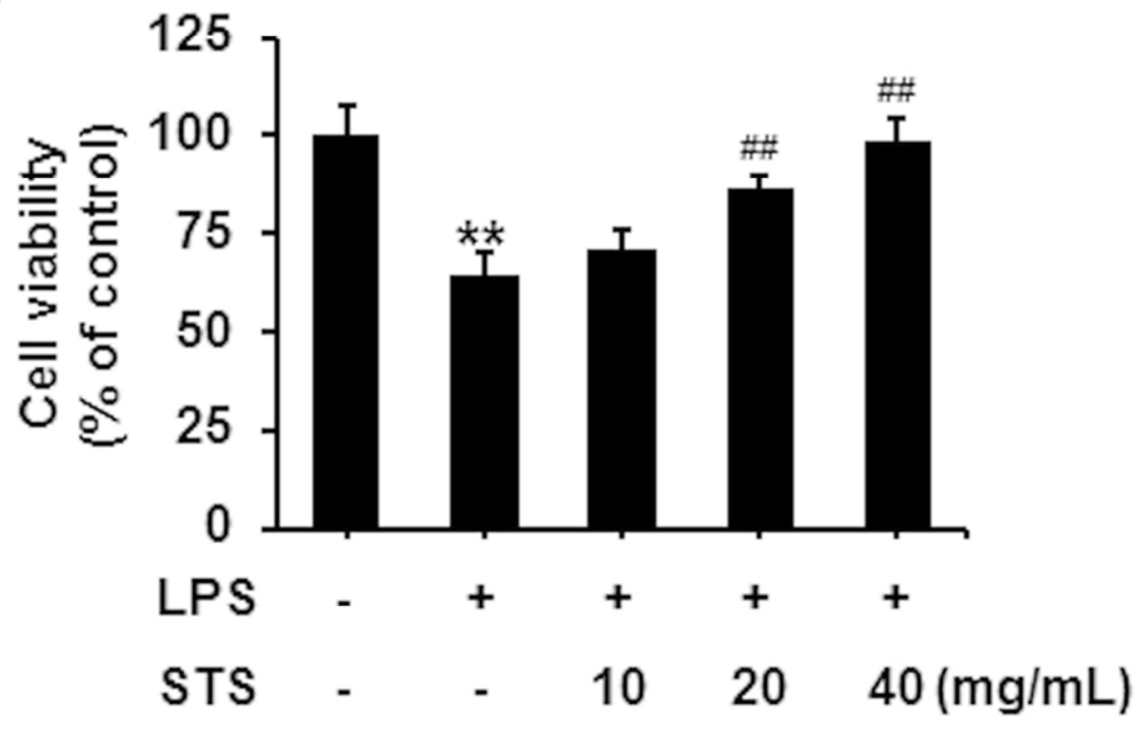

Fig. 2. Effects of STS on LPS-mediated cell viability. $69 \times 87 \mathrm{~mm}(300 \times 300 \mathrm{DPI})$ 

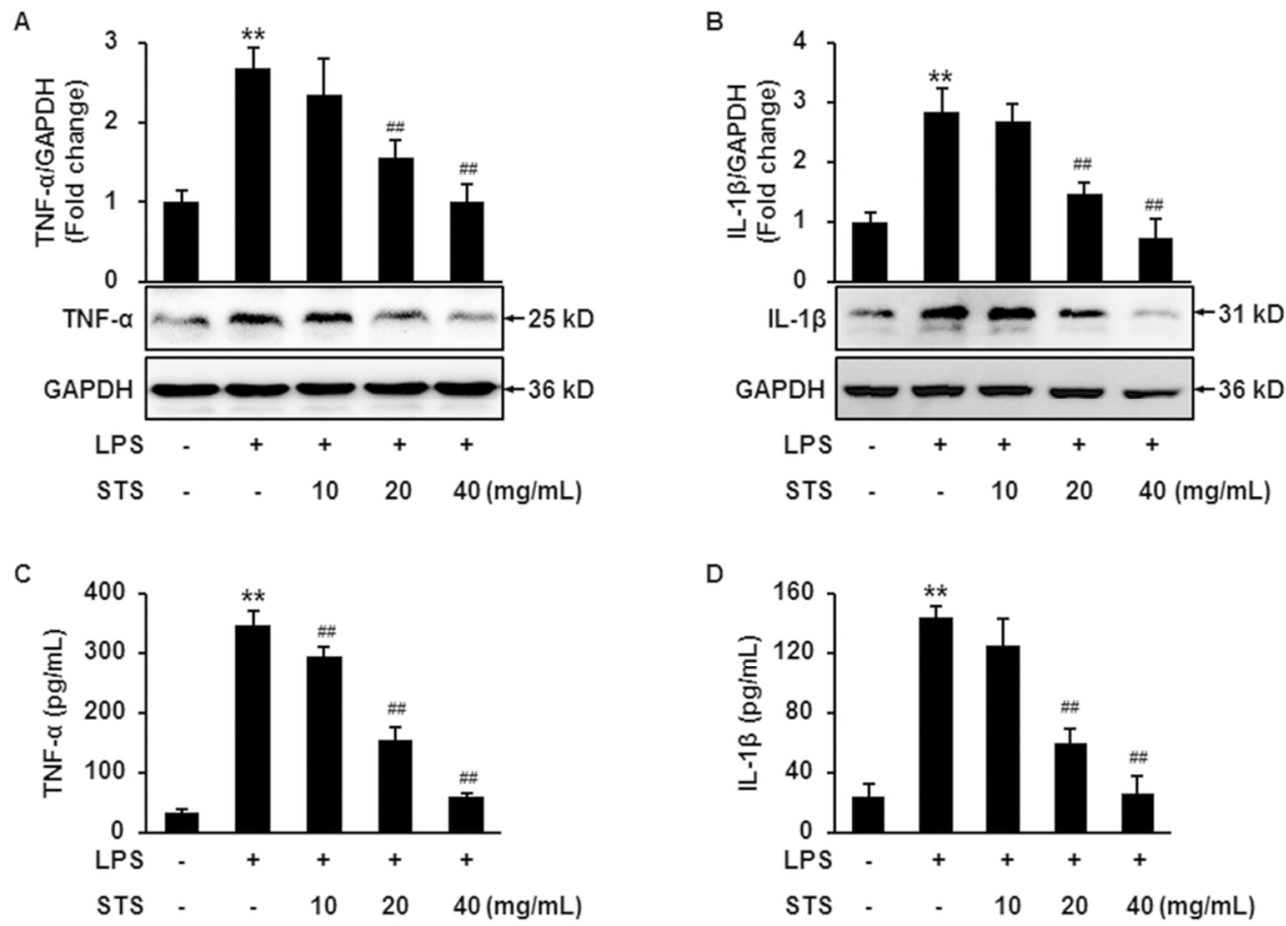

Fig. 3. STS prevents LPS-induced TNF- $a$ and IL-1 $1 \beta$ expression and secretion in HUVECs. $84 \times 60 \mathrm{~mm}(300 \times 300$ DPI $)$ 

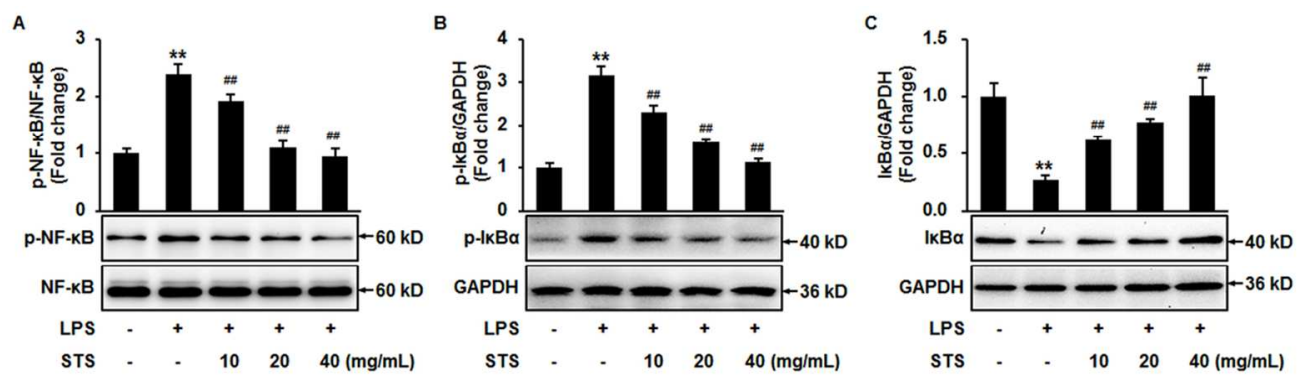

D
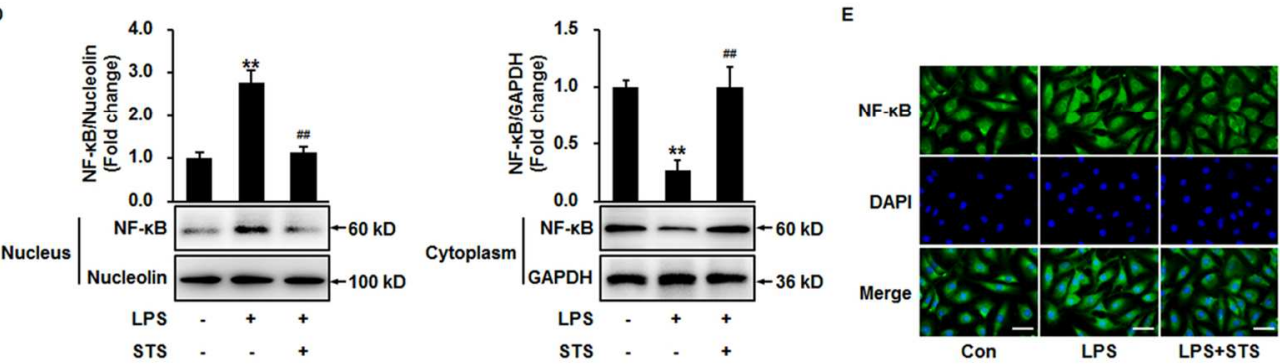

Fig. 4. STS prevents LPS-induced activation of NF-KB p65.

$107 \times 64 \mathrm{~mm}(300 \times 300$ DPI $)$ 

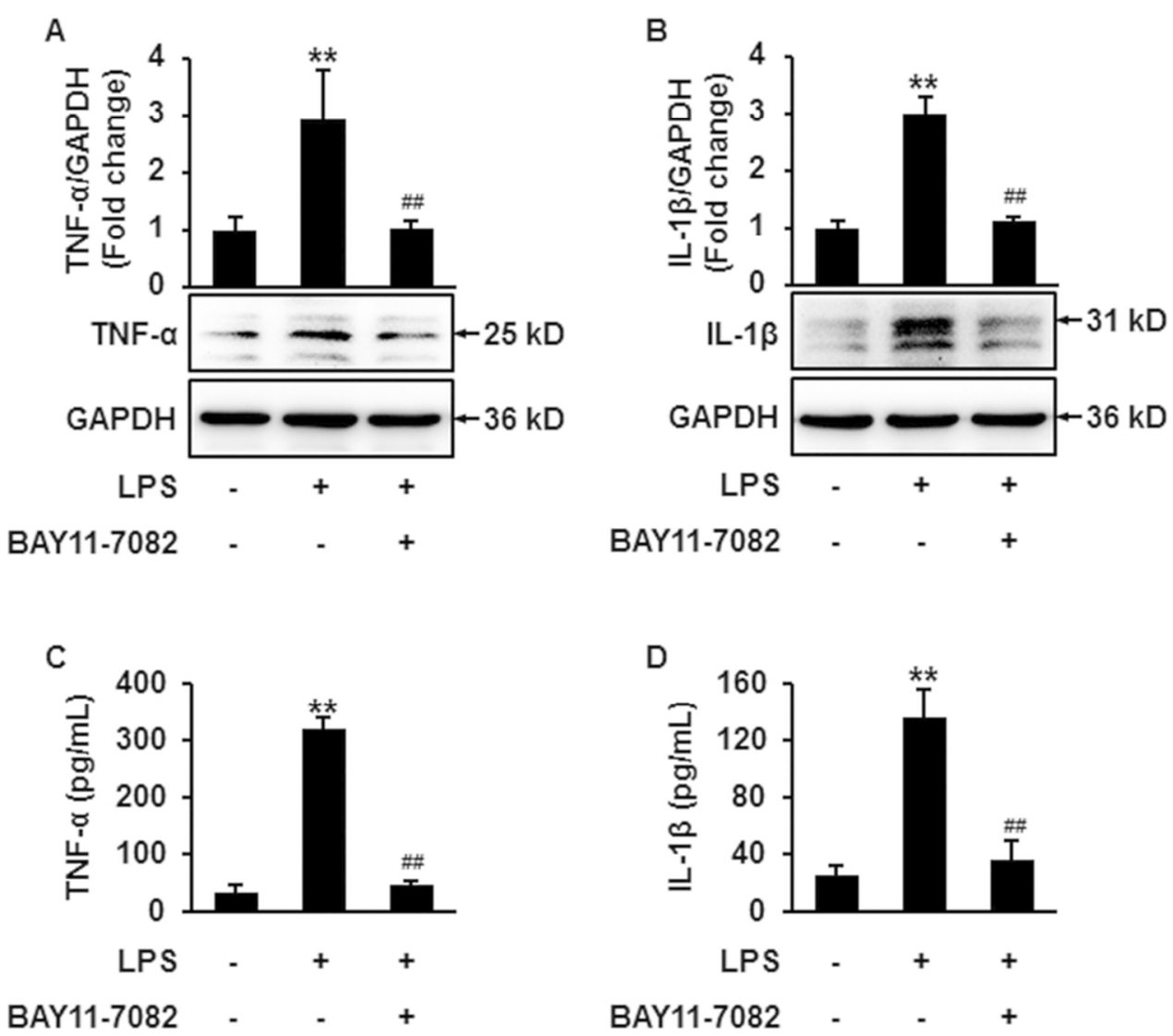

Fig. 5. BAY11-7082, the NF-KB inhibitor, inhibits LPS-induced TNF- $a$ and IL-1 $\beta$ expression and secretion in HUVECS.

$75 \times 65 \mathrm{~mm}(300 \times 300 \mathrm{DPI})$ 
A

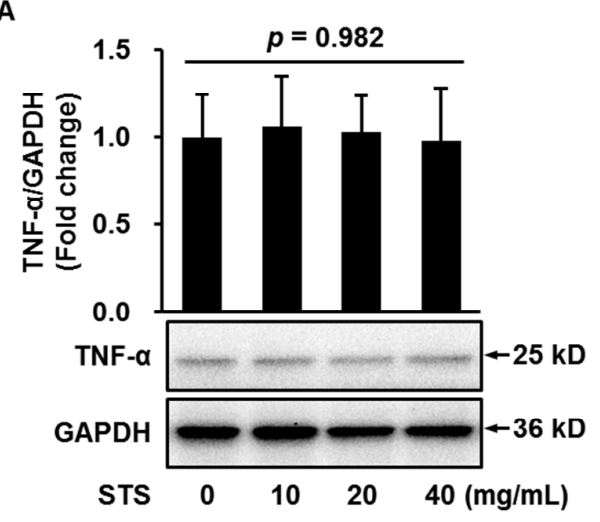

B

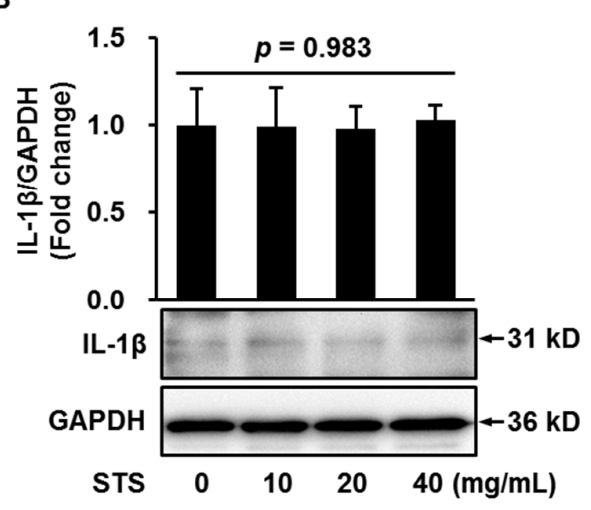

Fig. S1. The effects of STS on protein expression of TNF- $\alpha$ and IL-1 $\beta$. HUVECs were treated with STS $(0,10,20$ and $40 \mathrm{mg} / \mathrm{mL})$ for $24 \mathrm{~h}$ and expression of TNF- $\alpha$ and IL-1 $\beta$ was analyzed by western blotting. Representative images of 3 independent experiments and densitometric analysis of the levels of TNF- $\alpha$ and IL-1 $\beta$ normalized to that of GAPDH are shown. Data shown are mean \pm SD of 3 independent experiments, presented as fold changes. 
A

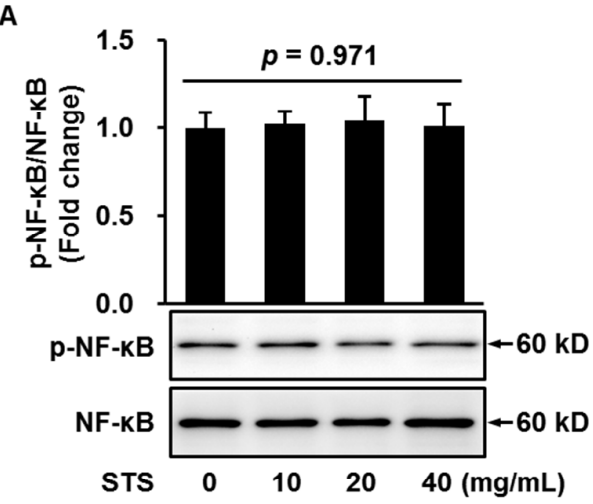

C

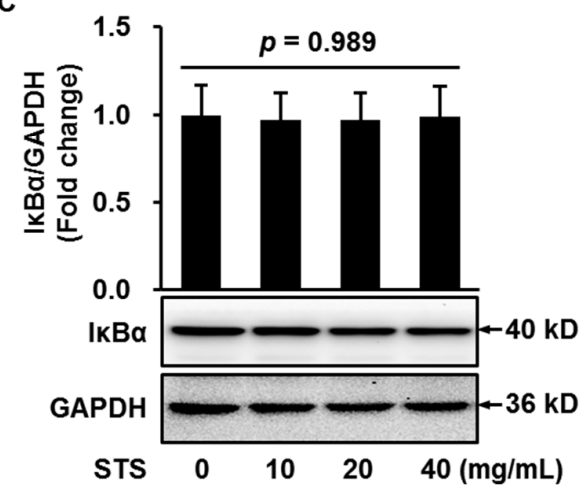

B

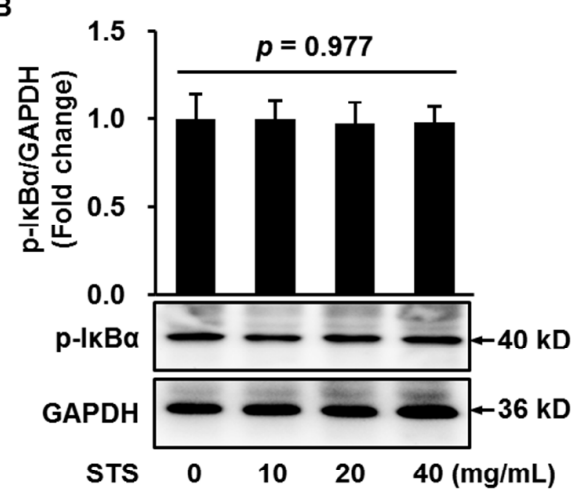

Fig. S2. The effects of STS on activation of NF-kB p65. HUVECs were incubated with STS $(0,10,20$ and $40 \mathrm{mg} / \mathrm{mL})$ for $6 \mathrm{~h}$. Cell lysates were prepared and subjected to western blotting to detect the phosphorylated $(p)$

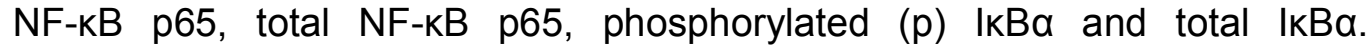
Representative images of 3 independent experiments and densitometric analysis of phosphorylated NF-kB p65 normalized to total NF-kB p65, phosphorylated IKBa normalized to GAPDH and total IKBa normalized to GAPDH are shown. Data are shown as mean \pm SD for 3 independent experiments and presented as fold changes. 